\title{
Editorial
}

\section{Deliberate practice and CPD in psychiatry}

\section{Dinesh Bhugra}

Abstract Deliberate practice (the seeking of situations in which one's skills are challenged and thus improved) is key to the acquisition of clinical expertise. This editorial outlines the philosophy of deliberate practice and potential difficulties in making use of it in psychiatry.

The difference between a competent and an expert clinician lies in a number factors. Both need a certain knowledge base and an understanding of the patient's experience of their distress and symptoms. However, the expert clinician has not only additional experience, but also a more focused knowledge base. Individuals need experience to become professionals, but extensive experience does not make people experts. Levels of attainment and retention of knowledge both depend on characteristics internal to the individual such as innate ability and mental capacity. However, a more significant factor in the quest for expert status is external and is known as deliberate practice.

Deliberate practice involves the construction or seeking of situations in which individuals are able to attain goals that exceed their current level of performance (Ericsson, 2004). The goal of deliberate practice is improved performance. Careful monitoring and problem-solving are integral parts of development in many fields (e.g. Gruson, 1988; Miklaszewski, 1989), not least in medicine in general and psychiatry in particular. Setting specific goals, obtaining immediate feedback and concentrating as much on technique as on outcome are three key components of deliberate practice.

Expert performance is mediated by complex integrated systems of representations, which include planning and carrying out a task, and monitoring and analysing its execution. Motivation to attend to the task and exert effort to perform repeatedly at a level that can be recognised objectively as excellent is a significant component of deliberate practice. The principal difference between acquisition of everyday skills and what in psychiatry we would call continuing professional development (CPD) or continuing medical education (CME) is related to difference in timescale (Ericsson, 2004). Professional development takes years (generally around 10 ) to become a reliable indicator of expertise (Ericsson et al, 1993).

Ericsson (2004) argues that various stages of learning are required to achieve expert performance in medicine. These include defining representative tasks that highlight the essence of the domain to be mastered. In the 'craft' specialties such as surgery or anaesthesia, the objective criteria are relatively clear, whereas in 'art' specialties such as psychiatry and general practice different issues emerge. Specialists must display deeper knowledge of diseases. However, knowledge about illness (i.e. how mental disease affects individuals and those around them) is equally important in psychiatry.

Deliberate practice is a highly structured activity, the explicit goal of which is to improve performance by investing in specific tasks to overcome weakness. Performance is carefully monitored to provide cues for ways to improve it further (Ericsson et al, 1993). Deliberate practice is not inherently enjoyable and requires effort, concentration and motivation.

Deliberate practice starts at a low level and increases slowly. The traditional view of deliberate practice assumes that certain people are drawn to fields in which they have innate ability to learn the associated skills. However, this is not always the case: not every professional has the ability to become an expert in their chosen field.

Motivational understanding is crucial in making sense of deliberate practice (Guest et al, 2001). This pertains to having the desire to improve and learn from the experience. In addition to motivation, effort constraint (directly related to the amount of practice) and amount of practice itself (Bloom, 1985) also play a role. Once everyday skills have been mastered, arrested development may follow (Ericsson, 1998)

Dinesh Bhugra is Professor of Mental Health and Cultural Diversity at the Institute of Psychiatry (PO Box 25, HSRD, Institute of Psychiatry, De Crespigny Park, London SE5 8AF, UK. Email: d.bhugra@iop.kcl.ac.uk) and President Elect of the Royal College of Psychiatrists. 
if either further experience or deliberate practice do not follow. Dissatisfaction with one's work appears to be necessary to motivate continual improvement, but although self-analysis and self-monitoring produce dissatisfaction, the latter by itself will not be sufficient to improve performance (Guest et al, 2001).

\section{Deliberate practice and the UK psychiatrist}

The theoretical framework of deliberate practice means that improvement in the performance of aspiring experts does not happen automatically but through changes in cognitive performance (Ericsson, 2006). Deliberate practice is designed to improve specific aspects of performance, which can be measured and integrated into representative performance. In deliberate practice, individuals concentrate in actively trying to go beyond their current abilities. For consultant psychiatrists in the UK who wish to use deliberate practice in CPD now and in recertification in due course, assessment tools for measuring it and its outcomes are essential. It is not always easy to measure outcomes (Ericsson \& Charness, 1994), and resources need to be identified and delivered. As part of CPD and of personal development, deliberate practice and peer development groups can (and should) be used to encourage, motivate, support and evaluate psychiatrists' efforts to deliver better clinical services.

\section{Declaration of interest}

None.

\section{References}

Bloom, B. S. (1985) Generalizations about talent development. In Developing Talent in Young People (ed. B. S. Bloom), pp. 507-549. Ballantine Books.

Ericsson, K. A. (1998) Basic capacities can be modified or circumvented by deliberate practice: a commentary. Behavioural Brain Science, 21, 399-442.

Ericsson, K. A. (2004) Deliberate practice and the acquisition and maintenance of expert performance in medicine and related domains. Academic Medicine, 79(10) (suppl.), S70-S81.

Ericsson, K. A. (2006) The influence of experience and deliberate practice on the development of superior expert performance. In The Cambridge Handbook of Expertise and Expert Performance (eds K. A. Ericsson, N. Charness, P. J. Petrovich, et al), pp. 683-704. Cambridge University Press.

Ericsson, K. A. \& Charness, N. (1994) Expert performance: its structure and acquisition. American Psychology, 49, 725-747.

Ericsson, K. A., Krampe, R. T. \& Tesch-Römer, C. (1993) The role of deliberate practice in the acquisition of expert performance. Psychology Review, 100, 363-406.

Gruson, L. M. (1988) Rehearsal skills and musical competence. Does practice make perfect? In Generative Processes in Music (ed. J. A. Slobodan), pp. 91-112. Clarendon Press.

Guest, C. S., Regehr, G. \& Tiberius, R. G. (2001) The life long challenge of expertise. Medical Education, 35, 78-81.

Miklaszewski, K. (1989) A case study of a pianist preparing a musical performance. Psychology of Music, 17, 95-109. 